\title{
Caminhos para o desenvolvimento de uma Sociologia das Homenagens
}

\author{
Rafaela Mascarenhas Rocha' \\ Recebido em março de 2021 \\ Aceito em junho de 2021
}

\section{RESUMO}

A construção de um subcampo dentro da Sociologia que trate sobre o processo de prestação e recebimento de homenagens passa por pelo menos dois conceito-chave e que serão abordados nesta discussão: a visibilidade e o reconhecimento de um indivíduo, se isso é dado ou conquistado junto ao meio social no qual ele está inserido. E pensamos as homenagens através de denominações de logradouros como um fragmento da história viva deste indivíduo e também operando como um sinônimo para visibilidade. Por isso, o caminho teórico traçado neste escrito inicia-se por Bergson (1990) e a conceituação de materialidade de memória, por ele definida; posteriormente adentramos ao estudo sobre memória coletiva desenvolvido por Halbwachs (2003). Em um segundo momento trazemos a noção de reconhecimento entre os indivíduos com base no estudo de Honneth (2003). Utilizando ainda a obra de Nora (1986) compreendemos o processo de homenagens através da denominação de logradouros públicos. Para assim estabelecermos uma reflexão sobre logradouros com nomes de imigrantes poloneses na cidade de Curitiba.

Palavras Chave: Homenagens; Memória; Reconhecimento.

\section{Pathways to the development of a sociology of tributes}

\begin{abstract}
The construction of a sub-field within Sociology about the process of providing and receiving homage passes by two key concepts at least and that will be addressed in this debate: the individual's visibility and the recognizing among the society, if it is given or conquered by the individual. We think the honors through naming addresses as a part of an alive history of him and operating as a synonym for visibility as well. For that reason, the theoretical path drawn in this paper begins by Bergson (2003) and his concept about memory materiality, developed by him. In a second moment we bring the recognizing notion between individuals with base in Honneth's study (HONNETH, 2003). Also using the work of Nora (1986) we understand the process of tributes through the designation of public places. In order to establish a reflection on streets with names of Polish immigrants in the city of Curitiba.
\end{abstract}

Keywords: Homage; Memory; Recognizing.

A proposta de iniciar a construção de um subcampo dentro da Sociologia que discuta questões referentes à prestação e ao recebimento de homenagens passa por pelo menos dois conceitos chave e que são abordados nesta discussão: o primeiro é a visibilidade

\footnotetext{
${ }^{1}$ Mestre em Sociologia pela Universidade Federal do Paraná. Email: rafaela_mrocha@yahoo.com.br.
} 
dada a um indivíduo e que se perpetua através da memória coletiva; e o segundo é o reconhecimento no meio social em que o indivíduo está inserido, como a sua história viva e que também opera como um sinônimo para visibilidade. Esse é um estudo que vem se construindo a partir de nossa tese de doutorado, apresentada em julho de 2021, sobre as homenagens públicas prestadas a imigrantes poloneses e alemães na cidade de Curitiba, com a denominação de logradouros.

A homenagem, neste caso, é o reconhecimento da memória. E para compreendermos melhor esta noção, abordamos o fundamento teórico sobre o tema, contido em Bergson (1990) e o conceito de Memória Coletiva elaborado por Halbwachs (2003) e quais são os componentes necessários para que uma lembrança pertencente a um grupo seja ele uma comunidade ou uma nação, se perpetue enquanto parte da memória deste grupo. Além disso, trazemos para essa discussão os escritos de Honneth (2003) sobre o processo intersubjetivo de reconhecimento social e como isso é conquistado, segundo o autor, por intermédio de um processo de disputa de espaço e notoriedade. Sobre os nomes que denominam endereços em uma cidade e a narrativa da trajetória neles contidas, é fundamental dialogarmos com Nora (1986) que traz uma história do tempo presente e define lugares de memória enquanto espaços — tal qual o é na presente pesquisa - físicos em uma cidade, dedicados a narrar uma trajetória individual ou de um grupo.

Como um delimitador do grupo social aqui estudado - os imigrantes europeus em Curitiba - revisamos brevemente os caminhos que a Sociologia da Imigração percorreu desde a sua elaboração pelos estudiosos da Escola de Chicago até a sua chegada ao Brasil e os trabalhos que Ianni (1966) elaborou na região de Curitiba em torno do grupo de imigrantes poloneses. Para então de forma suficiente discutir a proposta de um tratado geral para uma Sociologia das Homenagens e o que propomos com esse novo subcampo da ciência, que é compreender o processo de reconhecimento de imigrantes poloneses em Curitiba através da prestação de homenagens em logradouros públicos na cidade. 


\section{A Construção do Conceito de Homenagem na Sociologia}

Para se definir o que é homenagem e a visibilidade por ela gerada é fundamental começarmos o debate por Bergson (1990), que se debruçou sobre a questão da memória humana para além das definições do campo psicológico, considerando que o "passado sobrevive sob duas formas distintas: 1) Em mecanismos motores; 2) Em lembranças independentes.” (BERGSON, 1990, p. 84). E estes mecanismos motores de que o autor fala podem ser objetos ou imagens, que são, pois, representações do passado que se mantém no presente para ajudar a construir a lembrança na memória dos indivíduos, podendo ser por exemplo, relíquias e fotografias às quais os indivíduos recorrem para se lembrar de algo. O mesmo autor ainda classifica a memória propriamente dita como lembrança espontânea, que é aquela que não precisa de repetição para ser consolidada, sendo ela capaz de reproduzir fatos, datas e locais com perfeição (BERGSON, 1990). Em seguida, convém pensar na definição de memória coletiva desenvolvida por Maurice Halbwachs, que em A Memória Coletiva (2003) explica os caminhos para que uma lembrança individual seja construída a partir de contribuições de lembranças dos outros, uma vez que o indivíduo nunca está só em um acontecimento, sempre há testemunhas que podem se lembrar de mais informações e melhor de um ou outro detalhe daquele mesmo episódio, compondo fatos e frases, e assim reconstruir as memórias. Para o autor, quando as lembranças são memoradas por outros sujeitos presentes na situação, podem ocorrer modificações da impressão que o próprio indivíduo teve e de sua visão sobre o fato e segundo ele isso é comum e ocorre devido às imposições sociais, como pequenas correções no trajeto daquela situação. E mais do que isso, uma lembrança individual não seria de todo suficiente para que aquele fato se concretizasse na memória de um grupo, pois uma vez que a lembrança é individual, ela vem carregada de sentimentos e percepções que não podem ser compartilhadas entre o grupo. Mas se a reconstrução do fato em uma narrativa encontra pontos de convergência com outras versões e pontos de vista, contados por outros indivíduos também presentes no mesmo fato, essa lembrança tem mais chance de se tornar uma memória, pois nas palavras do autor: 
É preciso que esta reconstrução funcione a partir de dados ou de noções comuns que esteja em nosso espírito e também no dos outros [...] o que será possível somente se tiverem feito parte e continuarem fazendo parte de uma mesma sociedade, de um mesmo grupo. Somente assim podemos compreender que uma lembrança seja ao mesmo tempo reconhecida e reconstruída (HALBWACHS, 2003).

O que significa dizer que uma lembrança pode sim ter aspectos particulares para cada indivíduo que a vivenciou, mas elas estarão construídas sobre uma base comum entre os demais que também a vivenciaram. No entanto, não é necessário que todo um grupo esteja presente para referendar a lembrança com suas contribuições, apenas alguns membros que compartilham de um segundo espaço de convívio no momento da recordação já são suficientes para que a lembrança se consolide. Outro aspecto referente à lembrança e que o autor destaca ainda neste raciocínio é a surpreendente possibilidade de reconhecer uma figura ou um lugar visto no passado e poder recordar exatamente como estava naquele momento e como se sentia quando viu tal coisa. Para Halbwachs (2003) isto é possível devido a uma sequência de percepções que se tem ao se refazer exatamente o mesmo caminho de outrora. Então, a lembrança se constitui em um conjunto de reflexões que reúnem a memória e a percepção daquele momento. Percepções estas que, segundo ele, "limitam-se a reproduzir objetos exteriores, (...). Daí a convicção de que elas serviram unicamente para nos deixar em determinada disposição (...) favorável ao reaparecimento da lembrança.” (HALBWACHS, 2003. p. 53-54).

Outra importante noção utilizada por Halbwachs (2003) é a intuição sensível, ela pende entre a projeção individual de uma lembrança e a influência social sobre a memória do indivíduo, determinando o que deve ser lembrado e como. O autor chega a esta noção explicando que as lembranças independem das vontades dos indivíduos sendo, portanto, algo externo a eles, algo advindo dos ambientes por onde passou. Fala também em estados que estão ligados entre si na consciência do indivíduo, e que se tornam pontos de perspectiva, nos permitindo compreender que as perspectivas criadas pelos indivíduos são construtoras ou formuladoras das impressões ou sensações que cada um tem ou teve sobre um fato vivenciado. À primeira vista, a intuição sensível é percebida como um fenômeno individual, que genericamente pode ser atribuído ao 
esforço e mérito do possuidor da consciência, porém, segundo a explicação de Halbwachs (2003) ela é fruto da confluência de vários grupos influenciando na consciência do indivíduo.

Quando muitas correntes sociais se cruzam e se chocam em nossa consciência, surgem esses estados que chamamos de intuições sensíveis e que tomam a forma de estados individuais porque não estão ligados inteiramente a um e a outro ambiente, e então os relacionamos a nós mesmos (HALBWACHS, 2003).

A intuição sensível é, portanto, um conjunto de elementos - pensamentos, preferências, impressões ou lembranças - que não dependem do mundo exterior, no entanto não são elas próprias construções individuais, são sim marcas das influências que os indivíduos recebem dos grupos aos quais participam, recebem um pouco de informações de cada grupo, confrontam um ponto ou outro, para irem construindo eles próprios os seus constructos sobre uma lembrança.

Halbwachs considerou a memória como um resultado de representações coletivas construídas no presente, com a intenção de manter a sociedade coerente e unida (SANTOS, 2012, p.25) - muito próximo aos princípios definidores de sociedade para Durkheim - não considerando a memória um fruto da natureza individual mas levando em conta também as estruturas coletivas como geradoras das lembranças. E é a partir desta reflexão que a memória passa a ser também considerada como um objeto nas ciências humanas, além somente de um aspecto neurológico, pois parte de resultados de práticas reflexivas e processos interativos, ou seja, a partir de práticas sociais de forma geral (SANTOS, 2012).

E ao se ter em mente a ideia de materialidade de memória, de Bergson (1990), e as características definidoras de uma construída socialmente, colocadas por Halbwachs (2003), incluímos neste diálogo a proposta de Nora (1986) que trata sobre lugares de representação da memória, ou melhor, lugares onde ela se refugia, estando ligada a momentos e aspectos da história de um povo, segundo as próprias palavras do autor (NORA, 1986, p. 17). Ele estabelece primeiramente uma importante diferenciação entre a memória com base na conservação e transmissão de valores - aquela memória intocada que servia de base para as chamadas sociedades arcaicas, que por não recorrer a um passado, acabava por reconduzir eternamente a uma herança - e a que se quer debater 
com referência aos fatos históricos e constituintes de um povo. Para ele, desde que haja distanciamento e mediação sobre os fatos, não há mais essa memória dita intocada e verdadeira, mas sim a história. E define a história como uma reconstrução problemática e incompleta do passado, ou seja, apenas uma representação facetada deste. Assim, sua definição de memória também se baseia nesta condição de contribuições, lembranças e esquecimentos, como podemos ver nos trechos a seguir: "La mémoire est la vie, (...), elle est en évolution permanente, ouverte à la dialectique du souvenir et de l'amnésie. ${ }^{2 "}$ (NORA, 1986, p. 19). E também: "La mémoire [...] se nourrit de souvenirs flous, télescopants, globaux ou flottants, particuliers ou symboliques, sensibles à tous les transferts, écrans, censure ou projections3." (NORA, 1986, p. 19).

Pois bem, para o autor, os estudos de lugares de memória são em parte um movimento puramente historiográfico, em que um dos objetivos é um retorno reflexivo da história para dentro dela mesma. E então ele começa a listar alguns lugares de memória como ambientes da manutenção e propagação da história, como os museus, bibliotecas e o Pantheón ${ }^{4}$, por exemplo. E assim ele disserta sobre como a materialização da memória se constitui como algo valioso para a sociedade moderna e contemporânea, por meio das recentes técnicas de reprodução e conservação de documentos, e a facilidade em se documentar a história: lembrando que em nenhuma outra época se produziu voluntariamente tantos documentos quanto na sociedade contemporânea. Desta forma, Nora (1986) também faz a crítica de que se na sociedade ocidental contemporânea existe uma valorização maior daquilo que é novo em relação ao que é velho, que espaços reservados ao que é antigo sejam celebrados com nostalgia, na ânsia de se resgatar e preservar uma memória, que não é espontânea mas sim introduzida e celebrada socialmente, o que denuncia a existência de uma sociedade sem ritual, de acordo com seu raciocínio.

\footnotetext{
2 "A memória é a via (...), ela está em evolução permanente, aberta à dialética da lembrança e da amnésia." em tradução livre.

3 "A memória (...) se alimenta de lembranças desfocadas, telescópicas, globais ou fluidas, particulares ou simbólicas, sensíveis a todas as transferências, censuras ou projeções." em tradução livre.

${ }^{4}$ Pantheón de Paris está localizado no $5^{\circ}$ arrondissement da capital francesa, no prédio de uma antiga igreja católica construída por Luis XIV, para superar o tamanho da Basílica de São Pedro, em Roma. Este templo foi tomado pela Revolução Francesa e ganhou novo significado, para que passasse a servir como última morada dos heróis da França.
} 
Sobre os lugares de memória que trabalhamos neste artigo, Nora (1986) escreve um capítulo específico sobre os nomes de rua nas cidades francesas. Explicando que as denominações de vias públicas em vários locais daquele país acompanharam momentos históricos e dependeram fundamentalmente do grupo que estava no poder para se tornarem nomes oficiais. Como por exemplo, os nomes originários da Idade Média e que pareciam obscenos dão lugar a outros nomes considerados mais polidos, a partir do reinado de Henrique IV, no século XVII e essas substituições se dariam devido ao que Elias irá chamar de Processo Civilizador. Outro exemplo é quando acontece a Revolução Francesa, em 1789, em que a mudança política no país também se reflete nos nomes de logradouros, com a substituição daqueles nomes que faziam menção à monarquia ou à igreja católica. E desta forma, o autor descreve como os vários processos políticos da França foram determinantes para renomeações ou restauro de nomes de logradouros públicos que haviam sido renomeados pelo sistema político derrotado e substituído. Isso nos permite traçar uma reflexão comparativa com o caso brasileiro, pois quando ocorre a deposição da família imperial no Brasil e que dá início ao período republicano, em 1889, a junta militar que toma o poder faz substituições de nomes em importantes logradouros pelo país. E o exemplo curitibano que podemos citar é o da Rua da Imperatriz que passa a se chamar Rua XV de Novembro, no centro da cidade. Ou como em casos mais atuais, como nas iniciativas - por parte dos movimentos sociais ou de vereadores do campo democrático - de se substituir nomes de agentes da ditadura militar de 1964 presentes em endereços de várias cidades brasileiras.

O autor também faz uma contribuição importantíssima para a nossa discussão, quando diz: "Pour qui s'intéresse à la constitution des lieux de mémoire, les noms de rues pourraient peut-être servir d'indices, et ce à un double titre: comme manifestations de la mémoire collective d'une communauté et comme signes extérieurs de notoriété5" (NORA, 1986, p. 285). E é exatamente este caminho que pretendemos traçar em relação aos nomes de imigrantes nas ruas de Curitiba, observando onde está marcada a memória de um grupo e os casos de reconhecimento da notoriedade, sem que se exclua

\footnotetext{
5 "Aos que se interessam sobre a constituição dos lugares de memória, os nomes de ruas poderiam talvez servir de indícios, e de um duplo título: como manifestações da memória coletiva de uma comunidade e como símbolos exteriores de notoriedade." em tradução livre.
} 
uma e outra possibilidade. Porém, como Nora (1986) aborda basicamente nomes nacionais da política e intelectualidade francesas para vias públicas, e não considerando nomes de estrangeiros, ele destaca a força da narrativa do grupo no poder para que se consolidem as escolhas nas denominações, como neste trecho: "Plus nombreux sont, désormais, ceux qui considèrent que les noms de rues doivent ${ }^{6}$ représenter la mémoire collective - nationalle cette fois. Il ne s'agit plus, dans ce cas, d'un fond populaire qu'il faudrait sauvegarder, mais d'un répertoire officiel qu'il faudrait promouvoir7" (NORA, 1986, p. 285). Pois, se há um esforço para lembrar de algum nome, há também o mesmo no sentido contrário: o de esquecer, ou ainda o de promover o apagamento de um nome da memória coletiva, em favor de destacar outros. E como exemplo desta prática, Nora (1986) elenca alguns nomes que são muito contestados dentre os considerados heróis nacionais para servirem de denominação de logradouros em seu país: como Napoleão I, Richelieu e Luis XIV, e ainda aqueles que possuem má reputação e que são, portanto, evitados nas denominações de endereços, como o caso de Catarina de Médicis, Luís XV, Luís XVI e Napoleão III. O que aqui no caso brasileiro pode ser percebido por intermédio de nomes que são muito contestados pelos grupos no poder em períodos ditatoriais como os casos de representantes da resistência popular, como João Cândido ${ }^{8}$, Antônio Conselheiro ou Carlos Marighella, que jamais ganharam homenagens em vias públicas na cidade de Curitiba entre o período de 1964 a 1984, por exemplo. Ou ao contrário, os nomes de agentes repressores são considerados de má reputação em períodos democráticos, como o caso de Ernesto Geisel que não recebeu qualquer nome de logradouro em Curitiba entre os anos de 1988 até $2015^{9}$, por exemplo.

\footnotetext{
${ }^{6}$ Grifo do autor.

7 "Mais numerosos são, entretanto, os que consideram que os nomes de rua devem representar a memória coletiva - desta vez, nacional. Não se trata, neste caso, de uma base popular que deveria salvaguardar uma memória, mas sim de um repertório oficial que deveria promovê-la." em tradução livre.

8 João Cândido, também conhecido como o "Almirante Negro" foi um dos principais líderes da Revolta da Chibata no Rio de Janeiro, em 1910 - um protesto contra os castigos físicos que aconteciam oficialmente na Marinha do Brasil, mas somente àqueles marinheiros de pele preta, mesmo já sendo todos homens livres há mais de vinte anos. O João Cândido que se refere a praça no Centro Histórico de Curitiba, popularmente chamada de Largo da Ordem, homenageia um homônimo do Almirante, que foi um médico e escritor nascido na Lapa (PR) que ocupou o cargo de Presidente da Província do Paraná em 1907, segundo fonte da página da Casa Civil do Estado do Paraná, consultada em o9/10/2020.

9 Exemplificamos o ano de 2015 devido à data do Índice de Logradouros de Curitiba utilizado nesta pesquisa ser de 2014 e também por 2015 ser o ano anterior ao do início do processo de golpe de Estado, em curso no país desde 2016.
} 
Mas como não tratamos somente de homenagens a personagens ilustres nesta pesquisa, vamos agora adentrar ao conceito de reconhecimento social, a fim de compreendermos o que é necessário para que um personagem histórico tenha sua trajetória lembrada e reconhecida como homenageável em um meio social.

\section{O reconhecimento social}

Conforme indicamos anteriormente, a visibilidade de indivíduos de origem imigrante que cedem seus nomes a logradouros na cidade de Curitiba funciona como um sinônimo de reconhecimento social. E para aprofundar a compreensão sobre isso lançamos mão da obra de Axel Honneth Luta Por Reconhecimento (2003), um trabalho conceitual árduo em que o autor retoma o que segundo ele, eram apenas alguns esboços e esquemas feitos por Hegel em torno da ideia de que os sujeitos lutam por reconhecimento recíproco de sua identidade individual dentro da sociedade (HONNETH, 2003). O autor faz uma revisão teórica dentro do campo filosófico acerca da capacidade humana de estabelecer-se em comunidade, da luta individual pela conservação de identidade e os conflitos influenciados pelo poder ao longo da transição das sociedades antigas, para medievais e modernas, destacando a centralidade que a intersubjetividade tem na definição do que é reconhecimento social e afirmando que os comportamentos praticados em público são reconhecidos como expressão intersubjetiva das particularidades: "Só os comportamentos praticados intersubjetivamente e também efetivamente são capazes de fornecer uma base sólida para (...) liberdade ampliada” (HONNETH, 2003, p. 41). Falando em obrigações intersubjetivas como condição quase natural do processo de socialização, o autor chega ao conceito de reconhecimento, que se dá através de um entrelaçamento entre universalização e individuação, um movimento de ação recíproca entre os indivíduos que, desta forma, pode se aplicar dentro das relações comunicativas e ainda dá possibilidade para uma segunda onda de reconhecimento, que consiste na relação ética dos sujeitos possível de ser vista em processos de reconciliação e resolução de conflitos. O que passa diretamente pelo processo de luta por honra, ou seja, a validação de prestígio e reconhecimento que um indivíduo tem por parte do grupo em que está inserido e que o ajuda a se posicionar 
positivamente diante do grupo, automática e simultaneamente. "Honra é a postura que adoto em relação a mim mesmo quando me identifico positivamente com todas as minhas qualidades e peculiaridades" (HONNETH, 2003, p. 55). Especificamente sobre o processo de luta para se obter o reconhecimento, o autor a define como um processo de comunitarização social que força o mútuo reconhecimento. Como um processo de descentramento das formas individuais da consciência. É quando a consciência individual se entrecruza com as dos demais indivíduos, levando a uma consciência universal e, portanto, consensual, que capacita o outro a ter o mesmo reconhecimento garantido por mim. "O indivíduo só pode se proporcionar um sentimento de garantia a respeito de ser reconhecido por seu parceiro de interação mediante a experiência da reação prática com que aquele responde a um desafio deliberado" (HONNETH, 2003, p. 64). E este reconhecimento recíproco funcionaria, então, como um médium da universalização social.

No caso do processo de denominação de logradouros em uma cidade, acreditamos primeiramente que não se trata de uma homenagem direta ao indivíduo cujo nome está naquele logradouro, mas sim à sua memória e ao prestígio que sua trajetória alcançou. Denominar um logradouro em uma cidade pode ser tanto uma homenagem aos descendentes vivos daquele indivíduo como também uma iniciativa que parta destes. No endereço com o nome da pessoa homenageada encontra-se o registro de uma trajetória memorável e relevante para a cidade, como também uma referência ao grupo de pertença daquele indivíduo: sua família, seu local de trabalho, seu grupo cultural ou religioso, etc. Para ilustrarmos, basta observarmos a Rua Jerônimo Durski no bairro Bigorrilho, em Curitiba. Esta via foi assim denominada por meio de um decreto do então prefeito da cidade Ney Braga, em março de 1956. Quando a prefeitura urbanizou o caminho conhecido como Rua da Campina, fez a opção de oficializar o endereço dando a este o nome do imigrante polonês nascido em Poznan em 1824, que imigrou para o Paraná e na terra de adoção foi professor nas escolas das colônias polonesas, como Orleans e Campo Comprido e que faleceu na cidade de Campo Largo em 1905. Homenagem esta que não foi direcionada individualmente a Durski - pois ele havia falecido 50 anos antes - mas sim à trajetória deste imigrante e todo o grupo de imigrantes poloneses, então bastante numeroso nesta região da cidade, e que com isso o 
poder público local faz um movimento de reconhecimento àquele grupo. Outro exemplo está na Rua Rosa Saporski, no bairro Mercês, uma extensa via que homenageia a descendente de poloneses que também atuou como professora nessa mesma região da cidade. Rosa viveu em Curitiba entre os anos de 1895 e 1961, lecionou em escolas públicas da cidade e também foi diretora em estabelecimentos de ensino. A rua que leva seu nome foi a mesma em que ela viveu, e a inauguração oficial desta aconteceu em 1962 com a presença de seu filho, o então vereador Edmundo Leinig Saporski. Isso mostra que a homenagem envolveu os descendentes de Rosa, acontecendo inclusive com a contribuição do prestígio que seu filho obtivera na vida pública local.

Com este aparato trazido a partir de Honneth (2003) é possível compreendermos que tanto o homenageado quanto o prestador da homenagem devem ter alguma notoriedade, como é o caso dos vereadores de Curitiba que são responsáveis pelas propostas, tramitações e aprovações de cada nome que se tornará um logradouro oficial na cidade. Portanto, passamos a debater sobre os estudos refer entes às imigrações sob o ponto de vista do campo sociológico, a fim de compreendermos como este movimento de homenagear imigrantes por meio de denominação de logradouros é relevante e merece destaque, pois difere grandemente de uma homenagem prestada ao grupo luso-brasileiro - instalado há mais tempo no território - devido aos processos de integração social, ascensão econômica na terra de adoção e também a gradativa transição que estes grupos imigrantes obtiveram, partindo de uma situação de exclusão e preconceito para um caminho de luta por destaque social e o reconhecimento.

\section{O papel dos Estudos Migratórios em nosso objeto de estudo}

Em muitos estudos sociológicos que abordam populações imigrantes é possível perceber empasses e dificuldades de inclusão nas sociedades de adoção. Antes ainda da definição deste campo na Sociologia, é possível perceber que há uma postura habitual de se tratar a imigração como um "problema social", como pode ser observado na obra de Engels: A Situação da Classe Trabalhadora na Inglaterra (2008). É preciso retratar aqui, que neste texto, o autor tem um ponto de vista carregado de preconceitos sobre os trabalhadores irlandeses na Inglaterra, pois em termos gerais, ele coloca sobre os 
ombros dos trabalhadores irlandeses o peso de usarem abusivamente de álcool e da falta de acesso a bens culturais e educacionais, afirmando que a ignorância seria inerente ao povo irlandês. Retratando assim que a imigração era interpretada como um problema social, mas que posteriormente passaria a ser encarada como um processo humano e então compreendida como um direito. Uma sociologia das imigrações propriamente dita e estruturada como campo da sociologia começa a ser elaborada pelo grupo de estudiosos da Universidade de Chicago, que entre as décadas de 1920 e 1930 percebe o espaço urbano como um verdadeiro laboratório para a Sociologia. E é na cidade de Chicago, como também em Boston, que as populações imigrantes estão vivendo, ajudando a construir a vida urbana e também servindo como sujeito de pesquisa para vários estudos no campo da Sociologia. Destacamos aqui a obra Sociedade de Esquina (FOOTE WHYTE, 2005) em que o autor aplica a metodologia de observação participante, que até então era algo aplicado muito mais à antropologia, para integrar-se e estudar um grupo de jovens de origem italiana que vive em um subúrbio de Boston, sem receber políticas públicas específicas para sua educação, bem-estar e ingresso ao mundo do trabalho, muitos deles flertam com a marginalidade atuando em pequenos delitos e contravenções. Este é apenas um dos estudos desenvolvidos pela chamada Escola de Chicago, mas muito do que foi trabalhado nesta durante as primeiras décadas do século XX ainda serve de pilar estrutural da sociologia nos tempos atuais e que também nos serve de exemplo, pois se neste estudo Foote-Whyte está lidando com um setor marginalizado da sociedade urbana e o contraponto que temos em relação à pesquisa com logradouros que levam nomes de imigrantes diz respeito a indivíduos de grupos imigrantes que receberam homenagens em lograoduros públicos na terra de adoção. Porque embora existam diferentes perfis individuais dentre os homenageados - tais como o do médico oftalmologista e um dos fundadores da Universidade Federal do Paraná, o imigrante polonês Julio Szymanski, que dá nome a uma praça no bairro Rebouças, ou como o caso de Maria Homan Wisniewski que foi uma descendente de poloneses que atuou como parteira na colônia Dom Pedro e tem uma rua com seu nome na Cidade Industrial de Curitiba - verificamos que este é um processo público que legitima a presença destes indivíduos na cidade independentemente das trajetórias 
destes, e mais do que isso: os eleva à uma posição de destaque e relevância nas comunidades onde viveram e também no âmbito municipal.

Sobre os estudos referentes ao tema das migrações internacionais na sociologia brasileira, trazemos o trabalho de Ianni (1966) como um grande passo para o que se tem atualmente em termos de Sociologia das Imigrações no Brasil e, em específico, no caso das populações de imigrantes que adotaram o Paraná para viver. Em Raças e Classes Sociais no Brasil (1966) o autor observa Curitiba a fim de entender como se dava a vida de imigrantes e descendentes de poloneses nas chamadas colônias instaladas nos arredores da cidade. $\mathrm{Na}$ época desta obra, as antigas colônias de imigrantes poloneses ainda eram espaços rurais ou em processo de urbanização localizados distantes da área urbana, que seguia - esta sim - em acelerada expansão. Ianni então pode entender que algumas visões que partiam da população geral em Curitiba e se referiam ao caráter e a aspectos da vida social dos colonos poloneses, tais como seus hábitos religiosos e as preferências profissionais de maneira geral no grupo, eram bastante negativas. Parte dessas visões acabaram ficando registradas em obras de literatura como em contos de Dalton Trevisan, por exemplo, além de registros históricos que com o tempo foram superados, como o de Wilson Martins ${ }^{10}$. E também no imaginário popular, pois como o próprio Ianni (1966) mostra, grande parte do rechaço e do preconceito vividos pelo negro eram compartilhados pelo polonês em Curitiba: “(...) um informante nos prestou um esclarecimento que, de início, pareceu-nos um gracejo de mau gosto, tão inesperado foi. 'Aqui, afirmou, não há negros. O negro do Paraná é o polaco" (IANNI, 1966, p. 131). Outra depoente de origem alemã afirma o seguinte ao autor: "Não sei porquê tenho uma aversão especial por poloneses. (...) Acho os poloneses um povo atrasado, sem personalidade e muito traiçoeiro" (IANNI, 1966, p.132). Outros depoimentos presentes no estudo, vão associando o polonês ao negro, segundo o autor, e assim apresentando um inédito preconceito racial contra um elemento também branco e europeu, o polonês. Teria sido, enfim, essa a grande descoberta que Ianni fez a respeito das relações raciais no sul do Brasil, e lhe causara surpresa essa relação de rejeição do polonês por parte dos

${ }^{10}$ Referimo-nos ao livro Um Brasil Diferente escrito por Martins em 1953, ano de comemoração do centenário da emancipação política do Paraná e que por essa razão a obra teria recebido financiamento do governo do estado para sua elaboração. 
demais grupos europeus instalados em Curitiba e uma equiparação mesmo que de forma negativa deste grupo com o de pessoas negras, e que também pode ser visto em Oliveira (2015).

No entanto, essa visão preconceituosa com a qual Ianni se deparou não se sustenta quando olhamos para o grupo polonês sob outro aspecto: o poder associativista e organizacional que os imigrantes e descendentes de poloneses alcançaram em Curitiba desde os primeiros anos de sua chegada à capital paranaense. Algo que também foi abordado por Oliveira (2010) quando mostra que desde as décadas finais do século XIX os imigrantes poloneses construíram em Curitiba associações culturais e esportivas como por exemplo a Sociedade Polono Brasileira Tadeusz Kosciusko que em 2020 completou 130 anos de história. Como também criaram e mantiveram jornais e escolas para a difusão de informações em idioma polonês e a alfabetização das crianças da colônia, possibilitando à comunidade praticar o idioma materno. A educação das crianças para era considerada uma prioridade entre os membros das colônias polonesas em Curitiba. Essas iniciativas dão, deveras, outro contorno a esta populações de imigrantes e à discussão feita em torno deste grupo, pois sendo o exato oposto do que apregoava o estereótipo de que eles seriam iletrados, alcoólatras e ultracatólicos. Este perfil voltado para as práticas cultural, esportiva, informativa e educativa das associações ajuda a desconstruir a visão inicial que o próprio Ianni tivera e transmitira através das entrevistas coletadas em seu Do Polonês ao Polaco ${ }^{11}$. E que culmina no levantamento feito por nós, que indica a presença de 526 logradouros com nomes de poloneses - de um total de 9518 - espalhados por 60 dos 75 bairros da cidade de Curitiba, que foram oficializados entre os anos de 1958 a 2012 através de projetos de lei tramitados na Câmara Municipal de Curitiba ou de decretos do poder executivo local.

\section{Reflexões para uma Sociologia das Homenagens}

A proposta de um campo de estudo dentro da Sociologia que trate sobre homenagens leva em consideração o processo de reconhecimento social de um

\footnotetext{
${ }^{11}$ Artigo elaborado por Ianni como resultado de pesquisa e que se tornou um capítulo de sua obra Raças e Classes Sociais no Brasil, 1966.
} 
indivíduo, que no caso aqui estudado também significa falar em visibilidade destes perante a sociedade curitibana. A valorização de sua trajetória pelo seu grupo social e também o registro deste personagem na memória do grupo são fatores centrais para a obtenção de uma homenagem. Tendo em vista todo o levantamento da literatura que fizemos aaté o momento, acreditamos ser possível estabelecer que a memória em torno de um indivíduo seja preservada devido ao seu reconhecimento perante o grupo e que isso fique demarcado através de uma homenagem pública, como a colocação do nome desta pessoa em um logradouro público. No processo de denominação de logradouros em Curitiba, existe uma relação de reconhecimento da trajetória do imigrante ou descendente que parte ora da comunidade do bairro onde o homenageado viveu, ora parte do parlamentar que tem a iniciativa de prestar a homenagem sem que necessariamente se entre no mérito da grandeza de feitos ou da trajetória do homenageado. Em que se pode verificar homenageados de diferentes segmentos sociais e profissões, conforme exemplificamos anteriormente.

Há ainda que se considerar que o processo de reconhecimento do homenageado tem várias etapas no âmbito do poder legislativo responsável pela denominação de logradouros em uma cidade: primeiro o nome chega ao parlamentar via petição da população ou por iniciativa própria do parlamentar que já tinha no homenageado alguma referência positiva; e em seguida este reconhecimento é referendado na Comissão de Trabalho por onde o projeto de lei vai tramitar e finalmente no Plenário da Casa, por onde é aprovado - geralmente - sem polêmicas, pois não são nomes que feriram os direitos humanos, nem são pessoas ainda vivas, o que obedece os requisitos da Casa. O acesso dos nomes de origem polonesa ao status de nome de logradouro público se dá muitas vezes devido à presença de parlamentares que tem origem imigrante, visto que uma vez estabelecidos nos setores mais altos da sociedade estes começaram a ser eleitos e a propor nomes em logradouros para relembrar seus antepassados, principalmente a partir dos anos 1950.

No nosso ponto de vista, a narrativa predominante no ato de denominar um logradouro está posta em debate, principalmente no decorrer do ano de 2020 , quando movimentos sociais por igualdade racial colocaram em xeque figuras outrora homenageadas, mas que tiveram participação direta na escravidão de pessoas de 
africanas, entre os séculos XVII e XIX. Manifestações envolvendo derrubada de estátuas e bustos de líderes ou mudanças simbólicas de nomes de endereços representam uma disputa na narrativa sobre as trajetórias destes líderes. Pois se antes eram consideradas ilibadas e acima de qualquer possível mancha, uma nova leitura sobre essas trajetórias mostra que se tratam de membros de uma elite opressora e que tem tido a unanimidade questionada a partir destas manifestações. Contudo este é um debate ainda em construção, que embora seja relevante apresentar aqui, não necessariamente atinge os indivíduos estudados neste documento, pois a maior parte dos homenageados possuem biografias pouco conhecidas e portanto, pouco contestadas socialmente (NORA, 1986).

O maior desafio encontrado nesse processo de pesquisa é certamente conhecer as trajetórias dos homenageados, porque os projetos de lei para denominação de logradouros e que são apresentados na Câmara Municipal de Curitiba não possuem qualquer menção às biografias dos homenageados em suas justificativas, somente seus nomes, de maneira muito mais quantitativa, conforme apresentamos nos dados acima. Nos permitindo pensar que o movimento feito pelos parlamentares de origem polonesa foi o de demarcar a presença destes antepassados na cidade, ressaltando mais a sua coletividade do que destacando especificamente alguns perfis considerados relevantes, seja por eles próprios ou pelo grupo imigrante.

Este modelo de homenagem questiona inclusive se é necessária uma chancela parlamentar para que aconteça, fazendo pensar se uma iniciativa popular é capaz de substituir este processo. É possível, portanto, olhar para a história e ver movimentos de reconhecimento espontâneo da sociedade em torno de uma figura? Qual é a força da representação popular em um processo de reconhecimento e homenagem? E a chamada dívida histórica com personagens antes renegados, mas que conseguem ter sua trajetória positivada e reconhecida, isto tem efeito real na disputa e construção de narrativas históricas? São muitas as possibilidades a partir daqui. Mas talvez a mais importante e que leve este campo de estudo a se tornar uma proposta real e possível dentro da Sociologia é pensar o caminho que uma trajetória percorre até obter visibilidade no meio social em que está ou esteve inserida e através deste caminho chegar à obtenção da homenagem. Pensando inclusive se há uma mudança no conceito geral que o grupo faz sobre aquele indivíduo, como uma positivação gradual da avaliação coletiva sobre sua 
trajetória, por meio da análise de seus feitos; ou se há uma mudança na camada social do grupo como um todo, em que membros vão alcançando postos de visibilidade e assim levando seus iguais ao reconhecimento.

\section{Considerações finais}

A compreensão acerca da luta por reconhecimento social alcançado por imigrantes e descendentes de poloneses em Curitiba parte da percepção de rechaço e preconceito que este grupo recebera outrora e que aparece em registros de Ianni (1966) e Oliveira (2015). Observando como alguns membros deste grupo chegaram a uma homenagem pública como dar seu nome - ainda que postumamente - a um endereço na cidade e o prestígio que é ter o nome referenciado como um endereço na cidade. Como essas homenagens são na maioria das vezes póstumas - de acordo com a legislação local - fica a cargo dos descendentes a apropriação deste reconhecimento, que de fato verão o nome do antepassado ali reconhecido pela municipalidade. Contudo, como é possível verificar no estudo de Honneth (2003) esta notoriedade não se prende ao personagem homenageado postumamente, como também se estende aos seus descendentes e o reconhecimento mútuo parte e é aplicado a quem lhe presta a homenagem também.

Os passos para construir a memória coletiva de uma das capitais mais antigas do Brasil, passam pela opção de um tipo de narrativa sobre a contribuição que parcela imigrante polonesa foi grandemente reconhecida apesar de ter sido outrora rechaçada e preconceituada pela população local, como Ianni (1966) pode perceber. Esta narrativa reconhece que esse povo ajudou a desenvolver a economia da cidade na virada do século XIX para o XX e ela é possível muito devido à presença de parlamentares que tem origem descendente de imigrantes, visto que uma vez estabelecidos nos setores mais altos da sociedade, começaram a ser eleitos e a propor nomes em logradouros para seus antepassados, principalmente a partir dos anos 1950.

Apesar de uma suposta aleatoriedade na escolha e oficialização dos nomes, justificamos que o processo de tramitação dos nomes de logradouros em Curitiba, por mais consensual que pareça e seja, é um tipo de chancela que afirma o reconhecimento 
daquela trajetória e daquela personalidade, que ao se tornar um endereço é referendado diante de um rol de representantes do povo da cidade, tendo então estabelecido o mútuo reconhecimento, conforme está postulado em Honneth (2003). Há que se passar por um exame claro, que considere inclusive a ideia de honra e prestígio pessoal mediante o grupo social do indivíduo, em que o nível de grandeza alcançado é medido de acordo com seus feitos, como estabelece Honneth (2003).

O que aparentemente se coloca como central na denominação de logradouros em Curitiba é um reconhecimento póstumo ao grupo de imigrantes que outrora fora rechaçado e preconceituado como abusadores de álcool, possuidores de baixa escolaridade e alienação religiosa. Houve um esforço da Câmara Municipal de Curitiba encabeçado pelos vereadores de origem polonesa para oferecer logradouros públicos que levassem nomes de cidadãos ilustres e comuns desta origem. São indivíduos que contribuíram para a vida econômica, social, cultural e comunitária da cidade, atuando nas mais diversas profissões. A quantidade expressiva de 526 logradouros com nomes de poloneses, entre os mais de 9500 na cidade, nos ajuda a afirmar que a presença polonesa na capital paranaense que já foi bastante numerosa entre o final do século XIX e início do XX, foi também visibilizada por meio dessa alternativa.

\section{Referências}

BERGSON, Henry. Matéria e Memória. São Paulo: Martins Fontes, 1990. Cap. II.

BOLTANSKI, Luc; THÉVENOT, Laurent. De la Justification: Les économies de la grandeur. Paris: Éditions Gallimard, 1991.

CAPDEVILA, Luc; LANGUE, Frédérique. Entre Mémoire Collective et Histoire Officielle. Rennes: Press Universitaires de Rennes, 2009. Introduction e Cap. XIII.

FEDATTO, Carolina Padilha. Um Saber nas Ruas: o discurso histórico sobre a cidade brasileira. Tese (Doutorado em Estudos da Linguagem). Universidade Estadual de Campinas. Campinas. 2011.

FILGUEIRAS, Zuleide Ferreira. A Presença Italiana em nomes de ruas em Belo Horizonte: Passado e Presente. Dissertação (Mestrado em Estudos Linguísticos). Universidade Federal de Minas Gerais, 2011. 
FOOTE WHYTE, William. Sociedade de Esquina. Rio de Janeiro: Jorge Zahar Editora, 2005 .

HALBWACHS, Maurice. A Memória Coletiva. São Paulo: Editora Centauro, 2003.

HONNETH, Axel. Luta por Reconhecimento. São Paulo: Editora 34, 2003.

IANNI, Octavio. Raças e Classes Sociais no Brasil. Rio de Janeiro: Editora Civilização Brasileira, 1966.

NORA, Pierre. Lieux de Mémoire. Paris: Editions Gallimard, 1986. Intro e Cap. XL.

OLIVEIRA, Márcio Batista Silveira de. Organizações sociais dos Imigrantes Poloneses e seus descendentes em Curitiba (Brasil, 1890-1938). In: HECKER Alexandre e LIMA, Ismênia de. E/imigrações: histórias, culturas, trajetórias.org. $1^{\circ}$ ed. São Paulo: Expressão e Arte editora, 2010, pp. 83-99.

OLIVEIRA, Márcio Batista Silveira de. A Inesperada Descoberta de Octavio Ianni. Revista Sociedade e Estado, vol.30, n. 3. Setembro a Dezembro, 2015. p.799 a 817.

OLIVEIRA, Márcio Batista Silveira de; ROCHA, Rafaela Mascarenhas. Polish Names in Addresses in Curitiba (Paraná-Brazil): Homage, Recognition, and Visibility of an Immigrant Group. In: SARMIENTO, E.; SIUDA-AMBROZIAK, R (orgs.). Brazil-Poland: Focus on Migration. 1 ed. Niteroi: ASOEC-UNIVERSO; Varsóvia: ASC-UW, 2019.

ROCHA, Rafaela Mascarenhas. Curitiba Polonesa?: Um estudo sobre logradouros públicos dedicados a imigrantes e descendentes de poloneses (1951-2008). Dissertação (Mestrado em Sociologia). Universidade Federal do Paraná. Curitiba. 2016.

SANTOS, Myrian Sepúlveda. Memória Coletiva e Teoria Social. São Paulo: Anna Blume, 2012. Introdução e Cap. I.

SARTORI, Tríssia Ordovás. Ruas da minha cidade: Um estudo hodonímico. Dissertação (Mestrado em Letras, Cultura e Regionalidades). Universidade de Caxias do Sul, 2010. 